\title{
How health care contributes to climate change
}

\author{
Cite as: CMAJ 2019 April 8;191:E403-4. doi: 10.1503/cmaj.109-5722
}

Posted on cmajnews.com on Mar. 19, 2019.

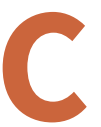

limate change is a growing health threat around the world - contributing to heat stroke, food insecurity, cardiorespiratory ailments and many other issues - and the health care industry is part of the problem.

"It's almost like the process of healing causes harm," said Kent Waddington, cofounder of the Canadian Coalition for Green Health Care.

Health care in Canada was responsible for $4.6 \%$ of national greenhouse gas emissions in 2009-2015, according to a recent study in PLOS Medicine. Given the rela- tionship between air pollution and human health, the researchers estimated that, every year, health care emissions result in 23000 years of life lost due to disability or early death.

Previous studies estimated that greenhouse gas emissions from the health sector in the United Kingdom and Australia represent $3 \%-4 \%$ and $7 \%$ of national emissions, respectively. In the United States, that figure comes closer to $10 \%$.

Pollution from the health sector can take many forms. Hospitals and pharmaceutical companies are the largest drivers

of emissions, according to the PLOS Medicine study. The authors also pointed to the impact of medical waste, unsustainable materials and anesthetics used in surgery, which are greenhouse gases.

The Canadian Coalition for Green Health Care has led projects to reduce the environmental impact of providing health care, such as promoting sustainable food in hospitals and reducing toxic chemicals used for cleaning. The coalition recently studied energy consumption by medical imaging equipment. Greenhouse gases released when patients and staff travel to hospitals and clinics are also part of the equation, said Waddington.

With so many different parts of the health care system creating pollution, from the cafeteria to the operating room, Waddington suggested that hospitals start "green teams" so people from different departments can work collaboratively. "You can't leave it up to a few people to resolve," said Waddington. "We all have a part to play in climate change and environmental stewardship."

Waddington has seen positive change since the coalition started in 2000 , when "green was literally a paint colour," not a "national movement." Still, he thinks there's a long way to go. "People are doing this off the side of their desks while they're doing their regular jobs."

For Dr. Jean Zigby, president of Synergie Santé 
Environnement, a nonprofit dedicated to reducing the environmental impact of Quebec's health care sector, the multifaceted nature of the problem means that solutions are everywhere. The organization sends consultants to hospitals to help reduce environmental impact, making recommendations such as upgrading heating systems to use geothermal energy, reducing food waste, improving recycling systems and encouraging staff to walk or cycle to work.
The health sector has immense purchasing power that can stimulate sustainable industries, added Zigby. "Physicians and health care institutions have enormous potential to rapidly shift from being consumers of environmentally degrading sectors to being drivers of the green revolution, because we have an ethical mandate to do no harm."

Unlike many business corporations held accountable by their boards to produce profits, medical institutions are account- able for the health of their communities. Zigby said there's been a "ground swell of desire" from health care workers across the country who want to see the industry operating more sustainably. To move forward in reducing the environmental footprint of the health sector, provincial governments could introduce mandates encouraging hospitals to become more environmentally friendly, suggested Zigby.

Caroline Mercer, Toronto, Ont. 